\title{
Research on Consumers' Attitudes towards Online and Offline Shopping
}

\author{
Xue $\operatorname{Yan}^{1}$ \\ ${ }^{1}$ University of Washington. College of arts \& science. Seattle. USA. 98105
}

\begin{abstract}
This paper collects data by means of questionnaire survey and analyzes the data to study consumers' psychological survey and the relationship between consumer characteristics and online and offline shopping, so as to speculate how to maximize their own interests for online and offline businesses. In the early stage, a wide range of data through questionnaires are used in this research. A total of 300 questionnaires are collected, 282 of which are valid. Excel and Python are used to analyze the relationship between various factors. The relationship between each other is inferred by analyzing the linear relationship and the data distribution. Through analysis, it shows that most people still prefer online shopping, which has become a development trend. Only a minority of consumers over the age of 30 remain enthusiastic about offline shopping. Most of the online products are clothes, cosmetics, skin care products, snacks, etc., while offline products tend to be fresh products, drinks, and clothing, etc. In addition, online shopping has become a trend in the future. Offline merchants should improve consumers' shopping experience by emphasizing more on the actual consumption experience and feelings brought by shopping and improve other supporting services that can be implemented offline to attract more consumers' offline shopping.
\end{abstract}

\section{INTRODUCTION}

In the research of Aron M. Levin and Irwin P. Levin and Joshua A. Weller, it is mentioned that consumers' online and offline shopping preferences vary with different products, consumers and stages of shopping experience. Their research sample shows that women are more likely than men to buy clothing online, while men are more likely than women to buy electronics and computer products online. Therefore, those who study individual differences in online shopping preferences need to consider that these may have different effects on different products, and conversely, for those who study product differences. But their subjects are more computer-literate and internet-savvy than the average consumer, so the absolute number of online shopping preferences may be higher than the average consumer. Therefore, a comprehensive study on consumers' online and offline consumption is more necessary. [3] In the study of Deborah Brown McCabe and Stephen M. Nowlis, Consumers are more inclined to purchase geometric products online than physical products.[4]

Besides, in 2020, COVID-19 suddenly happened. Faced with this disaster, most of them will be isolated at home, so many people have switched their shopping from offline to online. During this period, the trend of online shopping has increased wildly, including the stock price of some online shopping websites also has risen wildly. Offline brick-and-mortar stores gradually goes down, and some merchants face bankruptcy. Therefore, consumers' attitudes and psychology towards online and offline shopping are worth to research, so as to help online and offline merchants better improve their services to attract more people, so as to maximize their own interests and value. By studying the opinions of different types of consumers on online and offline shopping, as well as the categories of goods they consume, including some suggestions given to make a comprehensive arrangement, this research will provide some practical market suggestions to online and offline merchants.

\section{LITERATURE REVIEW}

Aron M. Levin and Irwin P. Levin and Joshua A. Weller mentioned that consumers' online and offline shopping preferences toward different products, consumers and stages of shopping experience would be different. Their research sample shows that women are more likely than men to buy clothing online, while men are more likely than women to buy electronics and computer products online. [3] In addition, Chayapa says the process of making decision are very similar for consumers no matter shopping online or offline. However, some differences about shopping environment and marketing behavior would influence consumers' choice.[6] Besides, in the study of Bukola Olamidun Falode, they mainly study online and offline shopping motivation of apparel consumers in Ibadan Metropolis Nigeria. They believe that most consumers prefer to shop offline. Consumers also shop online, and people who shop online also shop offline, so the percentage of people who only shop online

* Corresponding author:1215657479@qq.com

(c) The Authors, published by EDP Sciences. This is an open access article distributed under the terms of the Creative Commons Attribution License 4.0 
is very small. They believe that consumers prefer shopping as a happy activity, so some offline environmental factors will also affect their shopping experience.

Even though Internet technology can help merchants improve service quality, reduce costs, improve production efficiency and improve profitability, retailers still need to learn the combination of online and offline marketing strategies to maximize their value. A business should operate online and offline together, so as to maximize our own interests and value from target to all customers. But online shopping is better because the convenience and rapidity online can bring people cannot bring offline. And offline retailers do have some problems that need to be improved. Since consumers think shopping is happy, offline businesses should pay more attention to make consumers happy when shopping and shopping experience is happy, so as to attract more consumers to offline shopping.[1] According to the study by Raja Sarkar and Dr. Sabyasachi Das, there are significant differences in the way consumers shop online and offline media based on specific parameters in the Indian consumer group. While online sales are growing fast in India and the way of shopping is expected to rise further, most Indian consumers still prefer the so-called "real" shopping experience in brick-and-mortar stores.[2] In their research, Aron M. Levin, Irwin P. Levin and C. Edward Heath says that different products have different needs to increase their online or offline presence. However, consumers' continued exposure to online shopping may reduce their worries about online shopping and change the current situation. Some features of the online shopping experience are considered better, while some features of the offline shopping experience are considered better.

For example, a large number of choices and rapid access to information are considered ideal features for online shopping, while the ability to see touch processing products and personal services is considered ideal for offline shopping. Importantly, however, these features mean different things to different products. It should be a priority for marketers to continuously investigate the perceived advantages and disadvantages of online shopping capabilities. Product managers need to do more research like this to determine which features of the shopping experience are better provided by online or offline resources for their specific products, and at stage of the shopping experience these features come into play.

\section{Methodology}

\subsection{Research Area}

The study collects information on questions related to online and offline shopping from 282 Chinese consumers of different ages, occupations and genders. In this study, 300 respondents are randomly selected by a multi-stage method using a convenient sampling technique. Among them, 282 questionnaires are valid.

3.1.1 Data collection and procedures. The data are collected by questionnaire survey, and the questions are put forward by researchers according to the purpose of the study. The researchers distributed questionnaires through different online channels and screened out those questionnaires that they did not want to participate in or answer freely. Social Science Statistical Software Package (SPSS), version 20. Data are analyzed using 0 and Excel, and descriptive statistics such as frequency, percentage, and average are used. A total of 300 questionnaires are issued, but 282 are analyzed as 18 of them are improperly/incomplete.

\subsubsection{Results}

3.1.2.1 Social population and preferred shopping environment. The descriptive statistics of the samples are shown in Table 1, which provides the information of the respondents about Demographic information such as age, sex, education and work status. More female respondents (69.15\%), more than men (30.85), aged $19-30$ (41.13\%), followed by age 41 and above (38.30\%), 18 and below (11.35\%), 31-40 (9.22\%), mean age.

The respondents range in age from 19 to 40. Most of the interviewees are college graduates (61.36\%), $49.29 \%$ of undergraduate students, $12.06 \%$ of graduate students and $38.66 \%$ of $\mathrm{O}$ 'level students. More than half of the respondents are self-employed, 17.33 percent are unemployed. The results confirm that 66.31 percent of respondents prefer online shopping, while 33.69 percent prefer offline shopping.

TABLE. 1 SOCIO-DEMOGRAPHIC CHARACTERISTIC OF RESPONDENTS

\begin{tabular}{llll}
\hline & & Frequency & Percentage(\%) \\
\hline \multirow{3}{*}{ Sex } & Male & 87 & 30.85 \\
& Female & 195 & 69.15 \\
& TOTAL & 282 & 100.00 \\
Age & 18 and below & 32 & 11.35 \\
& $19-30$ & 116 & 41.13 \\
& $31-40$ & 26 & 9.22 \\
Education Status & 41 and above & 108 & 38.30 \\
\hline
\end{tabular}




\begin{tabular}{llll}
\hline & Undergraduate & 139 & 49.29 \\
& Graduate & 34 & 12.06 \\
& Postgraduate & 5 & 1.77 \\
& TOTAL & 282 & 100.00 \\
& Unemployed & 50 & 17.33 \\
& Self-employed & 15 & 5.32 \\
\multirow{3}{*}{ Employment Status } & Civil Servant & 33 & 11.70 \\
& Private Company & 38 & 13.48 \\
& Staff & 146 & 51.77 \\
\multirow{3}{*}{ Preferred Shopping } & Others & 282 & 100.00 \\
Method & TOTAL & 187 & 66.31 \\
& Online & 95 & 31.69 \\
& Offline & 282 & 100.00 \\
\hline
\end{tabular}

3.1.2.2 Description of consumers shopping frequency. The descriptive statistics of the samples are shown in Figure 1 and 2, which provides the information about the shopping frequency of consumers. As can be seen from the table, most consumers tend to spend less in the short term. $68.09 \%$ of consumers shop about once a week, 26.24 once a month and less than $10 \%$ once a quarter or once a year. What's more, most consumers spend less than 1000 YUAN per purchase, 16\% spend between 1000 and 5000 yuan per purchase, and less than $5 \%$ spend more than 5000 yuan per purchase.

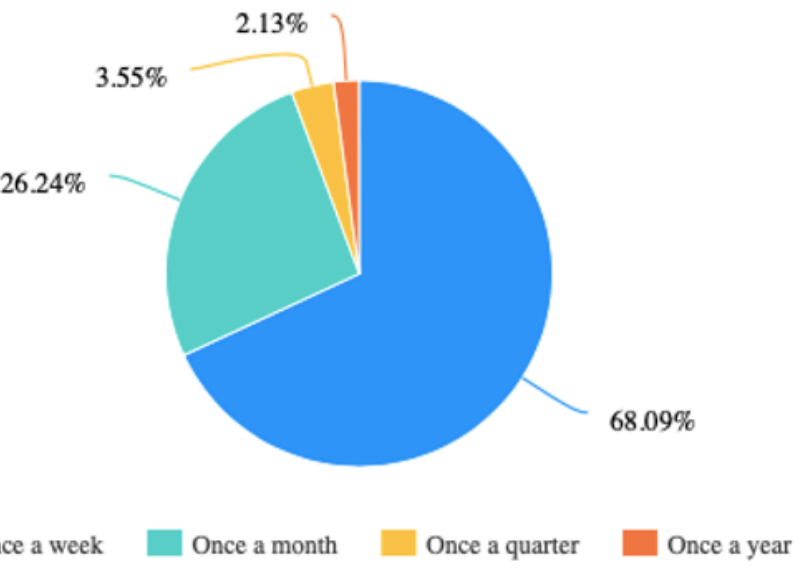

Figure 1. Consumer's shopping frequency for shopping

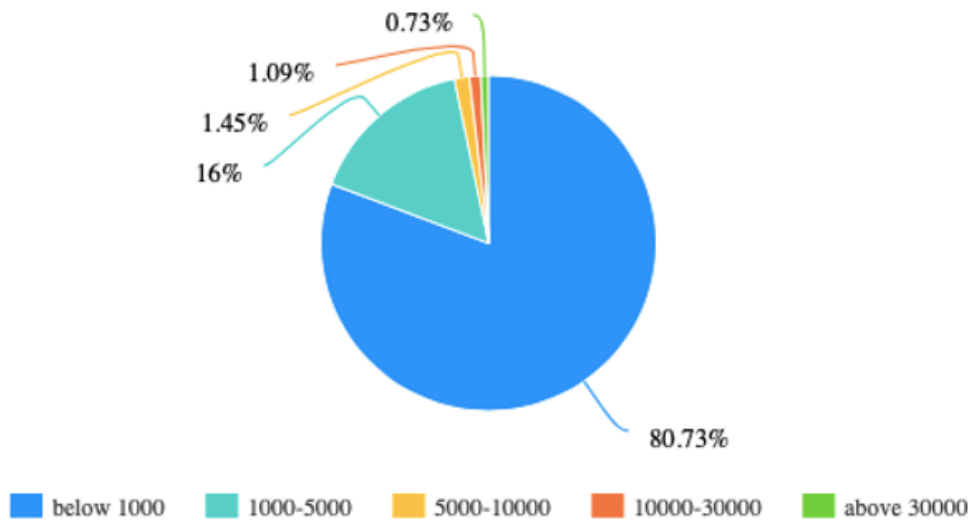

Figure 2. Consumer's shopping amount for one-time shopping

\subsubsection{Description of characteristic about} consumers related to shopping online and offline. The descriptive statistics of the samples are shown in the following figures, which provides the information about the relationship between consumers' characteristics and their preferences for online and offline shopping. As can be seen from the chart, online shopping has become a trend in all ages, occupations and educational backgrounds. Consumers of any type are more likely to shop online. Only among consumers aged 31-40 and those who spend once a quarter, online consumption tends to be the same as offline consumption. As an offline business, this group of people can be given priority. 


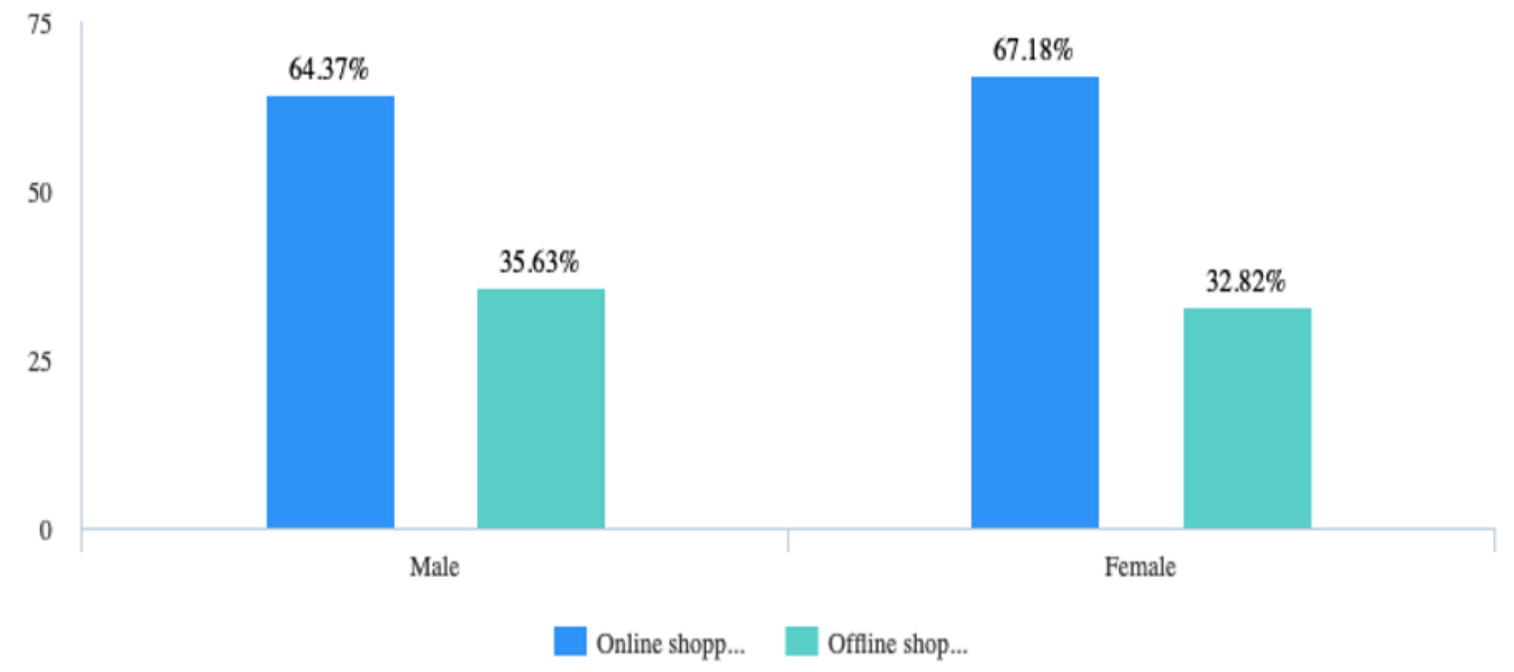

Figure 3. Relationship between gender and shopping preference

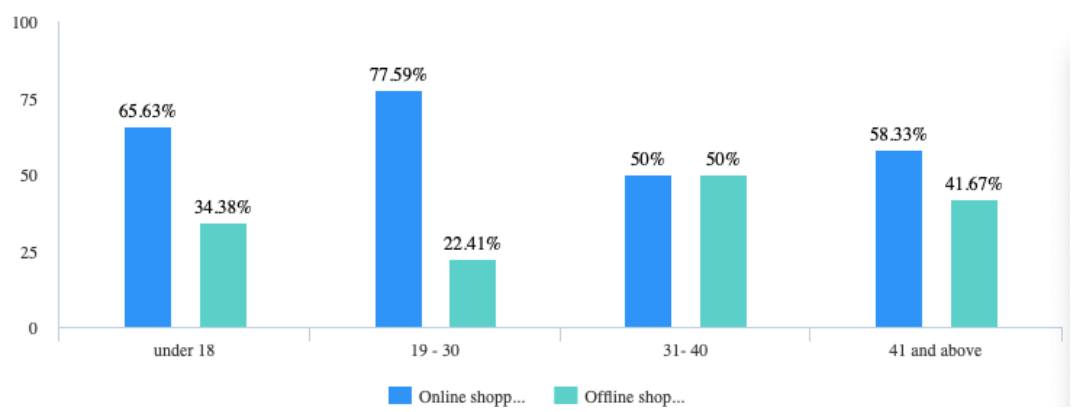

Figure 4. Relationship between age and shopping preference

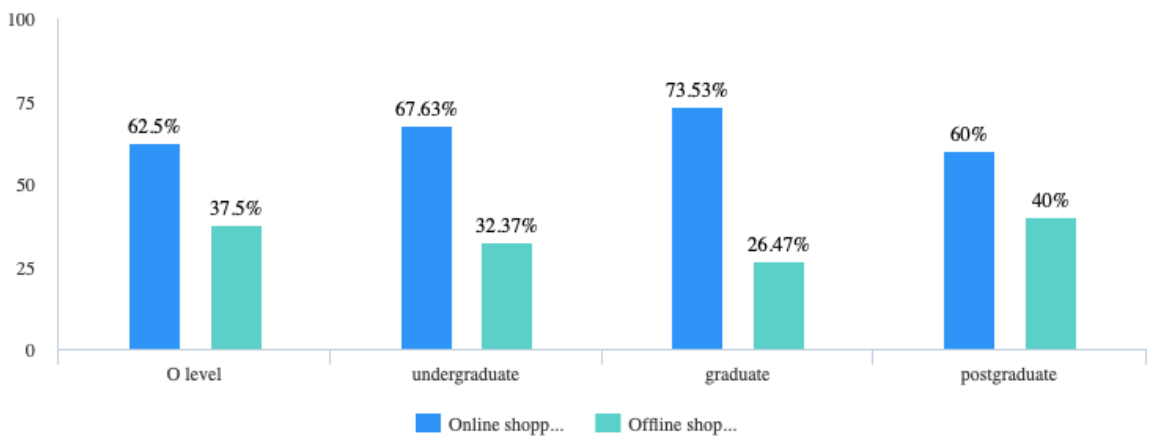

Figure 5. Relationship between education background and shopping preference

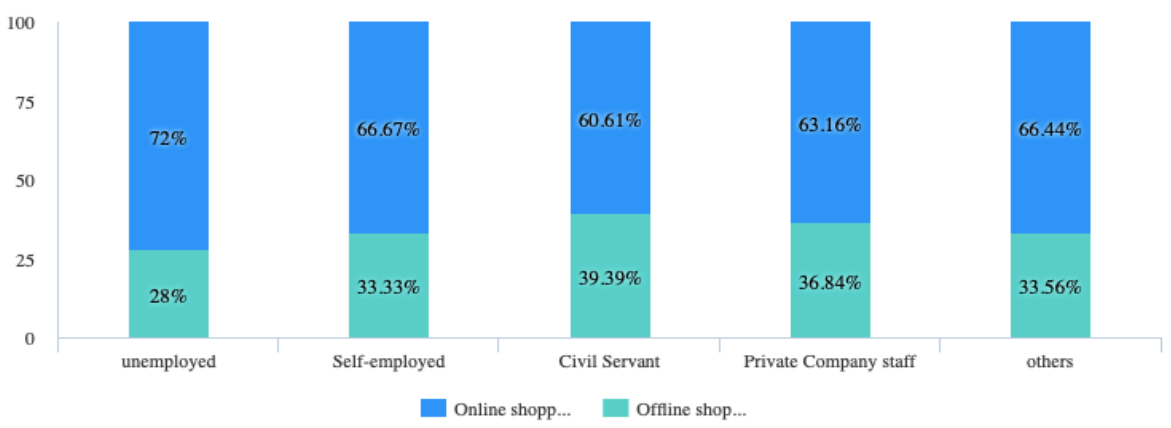

Figure 6. Relationship between working status and shopping preference 


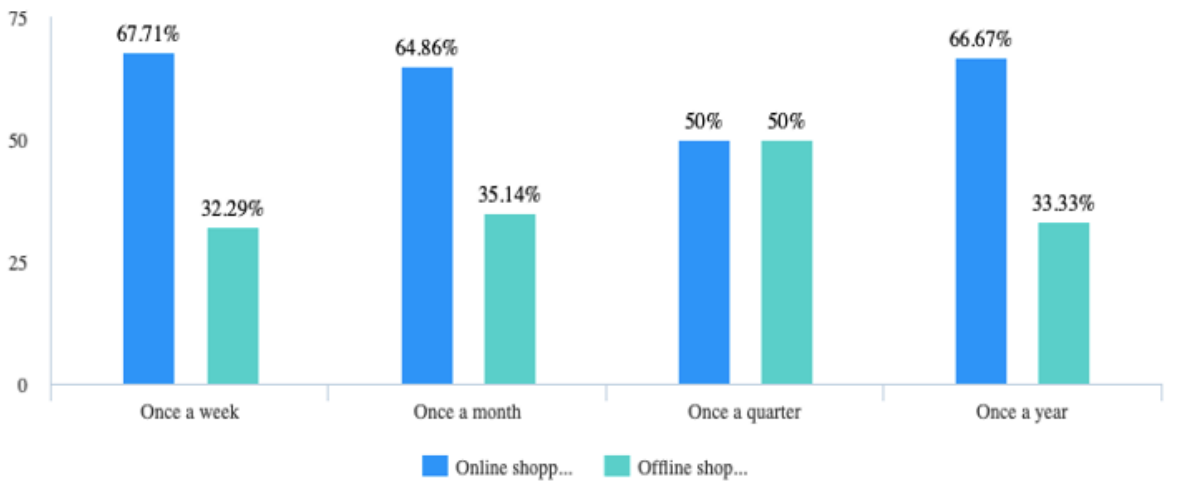

Figure 7. Relationship between shopping frequency and shopping preference

\subsubsection{Description of consumers' motivation of} shopping online and offline. The descriptive statistics of the samples are shown in Figure 8 and 9, which provides the information about consumers' consumption motivations both online and offline. The reason why more than $70 \%$ like online shopping is that they do not have to go out, so they can buy the products they like very quickly and conveniently. Another 60 per cent is due to the greater variety and discounts offered online. The reason why most people like offline shopping is that they don't have to wait for the transportation time, and they can try on clothes and buy clothes that fit them better. Part of the reason is that there are comprehensive shopping malls nearby, which can offer more brands and varieties.

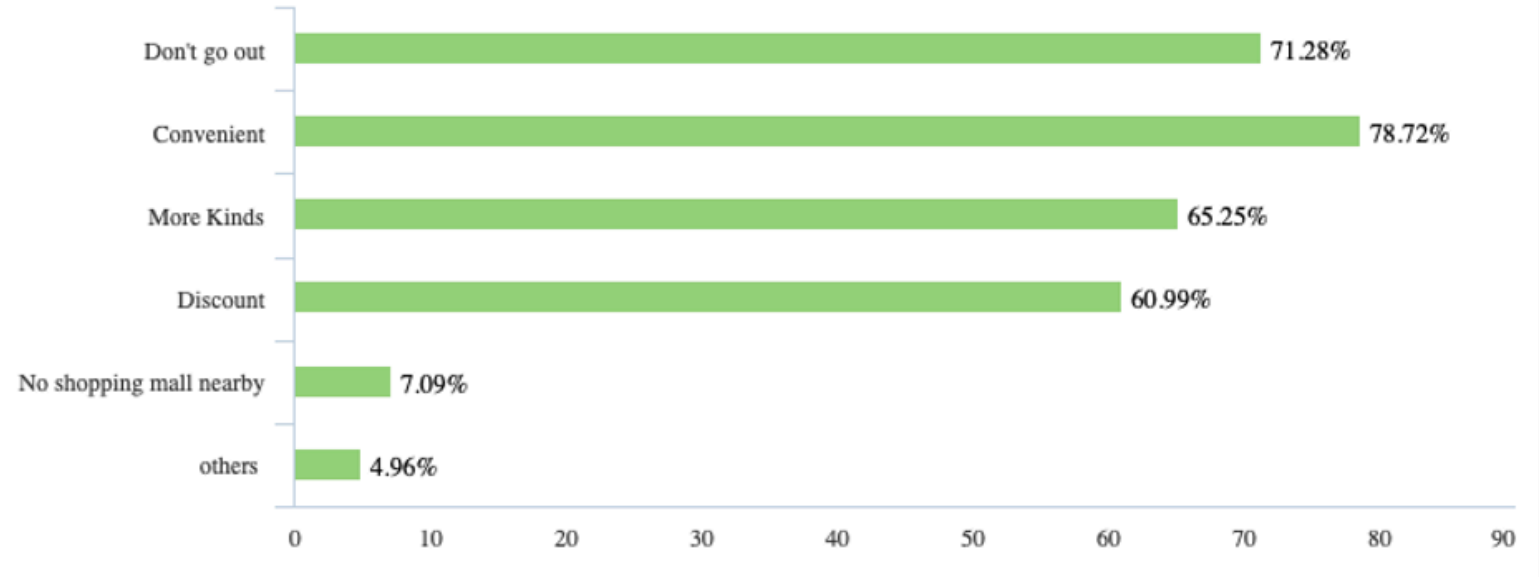

Figure 8. Consumer's motivation for shopping online

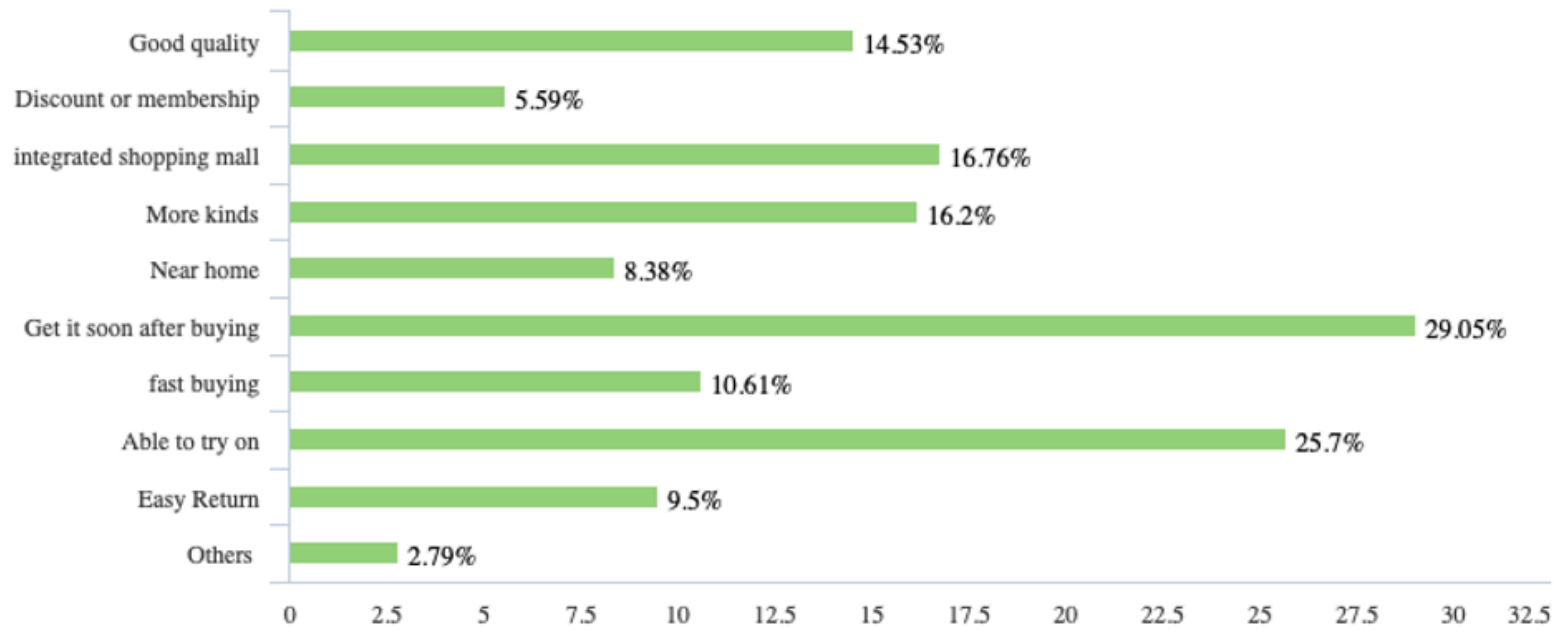

Figure 9. Consumer's motivation for shopping offline

3.1.2.5 Description of consumers preferred shopping categories of shopping online and offline. The descriptive statistics of the samples are shown in
Figure 10 and 11, which provides the information about consumers' online and offline consumption products. Most online shoppers prefer to buy clothing products, skin care products and cosmetics, as well as snacks. 27.3 
percent prefer to buy fresh products. Most offline shoppers prefer to buy fresh products, drinks and snacks, skin care products and clothing products.

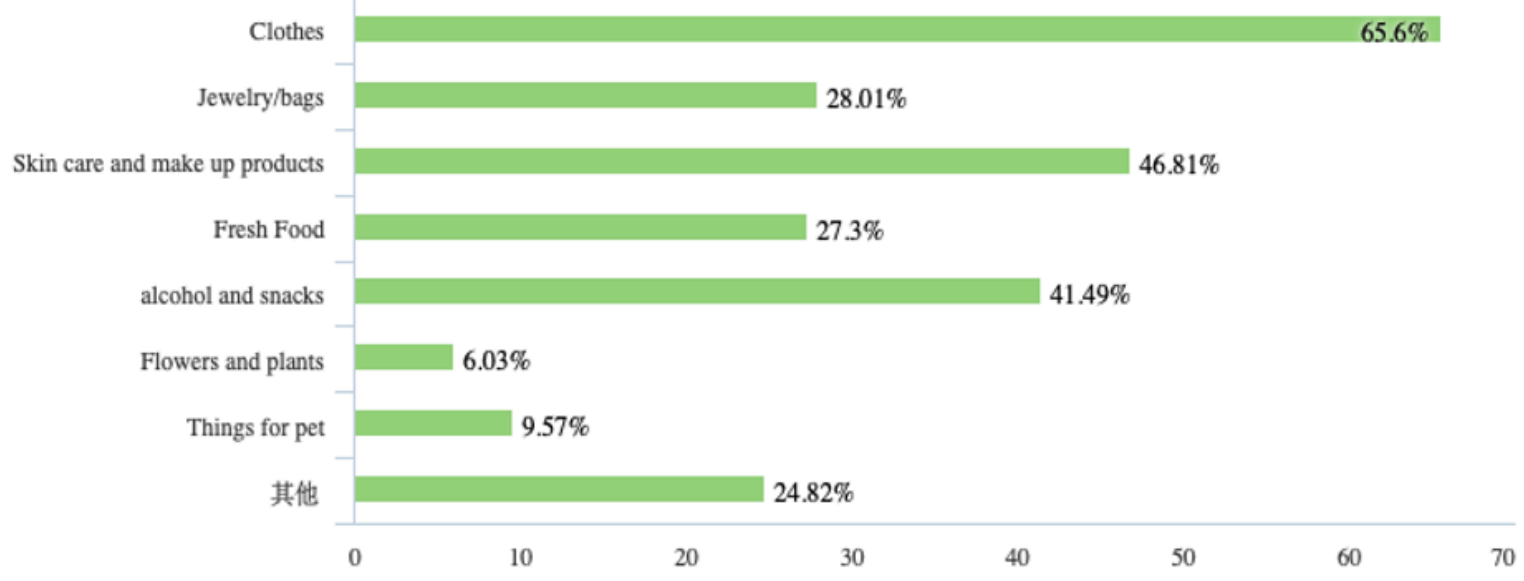

Figure 10. Consumer's shopping categories for shopping online

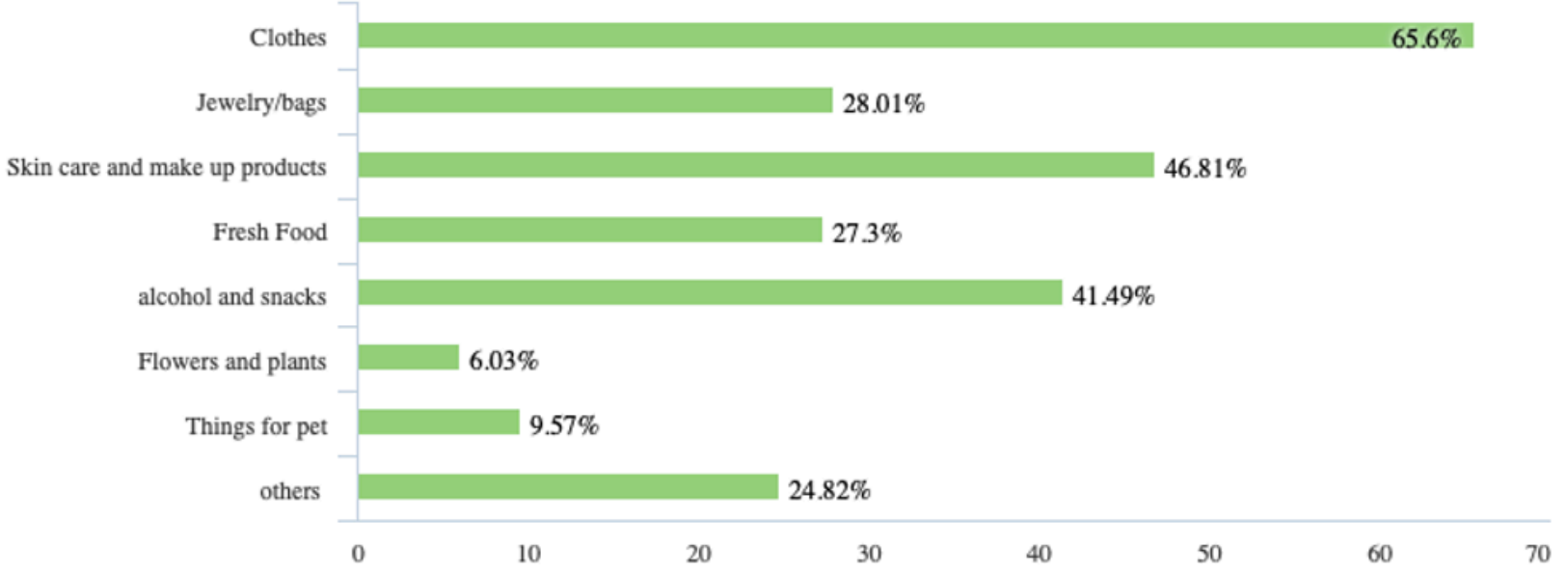

Figure 11. Consumer's shopping categories for shopping offline

\section{LIMITATIONS OF STUDY}

Due to the time, the number of questionnaires is only 282, which is not enough to represent the views and experiences of the majority of consumers. Moreover, there is a clear bias in age and gender distribution, which is not quite fair. What's more, more data is needed to reach a fair conclusion and some single-blind and double-blind experiments is also needed for obtaining real data and suggestions for improvement.

\section{CONCLUSION}

Online shopping has become a trend. No matter what age group, occupation, gender or education background, people are more inclined to online shopping. Because online shopping can bring more convenience to people, both in terms of the brands provided and the diversity of products, consumers can buy the most desirable products in the shortest time. The convenience brought by Internet technology makes the cost of merchants lower, so the discount of online shopping is also greater than that of offline shopping. The advantages of convenience and low price brought to online merchants undoubtedly make online shopping an inevitable trend. However, there is still a demand for offline shopping among consumers aged 31-40 years old and whose shopping frequency remains once a quarter. In the follow-up visits, offline merchants will conform to the consumption frequency of this type of consumers according to the different new styles in each quarter, and they pay more attention to the offline shopping experience and experience.

In addition, in the results, the advantage of offline shopping is that consumers can save the waiting time by taking the products right after buying. You can also try on clothes in physical stores to find the most suitable clothes to reduce the possibility of returning and changing and waste time and energy. With the establishment of comprehensive shopping malls, the types and brands of offline shopping are gradually increasing, which is not inferior to online shopping. In addition, in order to seek for consumers' opinions on offline shopping improvement, consumers also mentioned some problems related to consumption experience, such as the service attitude of shopping guides and parking services around them. Therefore, there is still a need for offline shopping. 
As mentioned above, consumers think shopping is a happy thing. So as offline businesses should pay more attention to the consumer's shopping experience and experience, merchants can hold some offline activities appropriately, guide or exclusive, or use the AI artificial change clothes, and so on tool to enrich our offline shopping experience, and at the same time advertisements can also urge you to go out, and friends to shopping, through the perspective of social to call for people to offline shopping, online shopping to feel can bring social experiences and shopping experience.

\section{ACKNOWLEDGEMENT}

During the research, Dr. Coggeshall plays an important role and provides tremendous amount of help whether in class or out of class. He discusses the related content, gives plenty suggestions while selecting topics, and uses reality as examples to explain vague definitions. Besides, he teaches the basic technique of Excel and Python while processing the data with patience. In addition, Dr. Coggeshall provides professional advice on writing academic paper and researching related resources. Thanks for guidance from Dr. Coggeshall.

\section{REFERENCES}

1. Bukola OlamidunFalode', Adetoun Adedotun Amubode, Mojisola Olanike Adegunwa \& Sunday Roberts Ogunduyile. Online and Offline Shopping Motivation of Apparel Consumers in Ibadan Metropolis, Nigeria.. 2016.

2. Raja Sarkar, Dr. Sabyasachi Das. Online shopping vs Offline Shopping: A comparative Study. 2017.

3. Aron M. Levin, Irwin P. Levin, Joshua A. Weller A MULTI-ATTRIBUTE ANALYSIS OF PREFERENCES FOR ONLINE AND OFFLINE SHOPPING: DIFFERENCES ACROSS PRODUCTS, CONSUMERS, AND SHOPPING STAGES. 2005.

4. Deborah Brown McCabe, Stephen M. Nowlis. Information Integration Across Online and Offline Shopping Environments and Its Effect on Consumers' Purchase Decisions

5. Aron M. Levin, Irwin P. Levin, C. Edward Heath. PRODUCT CATEGORY DEPENDENT CONSUMER PREFERENCES FOR ONLINE AND OFFLINE SHOPPING FEATURES AND THEIR INFLUENCE ON MULTI-CHANNEL RETAIL ALLIANCES. 2003.

6. Chayapa. K. Online shopper behavior influences of online shopping decision. 2011. 